\title{
New ten varieties and five subspecies of Crocus baalbekensis K.Addam \& M. Bou-Hamdan (Iridaceae) endemic to Lebanon added to the Lebanese flora
}

\begin{abstract}
Fifteen new world record Crocus baalbekensis var. decorus, fluctus, flavo-album, makniensis, youninensis, rasbaalbekensis, rihaensis, shaathensis, shlifensis, tnaiyetensis, subsp. ahlansis, anthopotamus, fakihansis, harbatansis, and rassomensis, joined the Lebanese flora and particularly the Iridaceae family. They were found in Baalbek-Hermel from North Baalbek to Hermel. All of them display C. Baalbekensis but vary in many taxonomic details. The validation for the existence of these new Varieties and Subspecies were verified by illustrated morphologic descriptions and observations were based on fresh materials. More than twenty years of fieldwork and three years of observation, phenology, and exploration of a host of locations, numerous quantities were found varying mostly from ten to more of the new species. Voucher specimens of the plants (Holotypes) were deposited in K. Addam's Herbarium at Arts, Sciences and Technology University in Lebanon.

The goal of this study was to display a comparative account on the anatomical and ecological characters of the 10 varieties and 5 subspecies of Crocus baalbekensis taxa as well as highlight the taxonomical importance of their corm, corm tunic, leaves, measurements, and comparisons of other structural anatomical differences and similarities.
\end{abstract}

Keywords: crocus baalbekensis var. decorus, fluctus, flavo-album, makniensis, youninensis, rasbaalbekensis, rihaensis, shaathensis, shlifensis, tnaiyetensis, subsp. ahlansis, anthopotamus, fakihansis, harbatansis, and rassomensis, iridaceae, taxonomy, Baalbek region, Lebanon, Mediterranean

\author{
Volume 4 Issue 6 - 2019
}

\author{
Khodr Addam,' Mounir Bou-Hamdan, ${ }^{2}$ Jihad \\ Takkoush, ${ }^{3}$ Kamal Hout ${ }^{4}$ \\ 'Head, Integrative and Environmental Research Center, AUL \\ Beirut, Lebanon \\ ${ }^{2}$ Integrative Research and Environmental Center, AUL Beirut, \\ Lebanon \\ ${ }^{3}$ Business Research Center, AUL Beirut, Lebanon \\ ${ }^{4}$ Department of PG Studies \& Scientific Research, Global \\ University Beirut, Lebanon
}

\begin{abstract}
Correspondence: Dr. Khodr H Addam, Head, Integrative and Environmental Research Center,AUL, Beirut, Lebanon, Tel 03 204930,Email dradda@hotmail.com
\end{abstract}

Received: November 19, 2019 | Published: December 05,

2019

\section{Introduction}

In the sixties, Lebanon was characterized worldwide as "Green Lebanon" due to the forests that cover this small country. ${ }^{1}$ Nowadays, Lebanon is regarded as a reserve for many exceptional and widespread native flora. It encompasses a renowned global center of plant diversity and one of the most stirring spots of conservation in the world. ${ }^{2,3}$ For these factors, Lebanon is considered as one of the most prosperous countries in its native flora holding more than 3150 plant species among all the Mediterranean countries.,

Lebanon's geological upbringing, auspicious distinctive idiosyncratic Mediterranean climate, and topographical diversity makes it one of the most affluent Mediterranean countries and a vital reserve for a myriad of infrequent, native and endemic species especially some of the very erratic endemic Crocus, Colchicum and Romulea. ${ }^{6}$

Lebanon constitutes of five geomorphological regions: The Coastal zone, which is around $250 \mathrm{~m}$ high, Mount Lebanon range which ranges between $250 \mathrm{~m}$ and $3088 \mathrm{~m}$, Anti-Lebanon Range, whereby its peaks reach a height of $2600 \mathrm{~m}$, Beqaa plain, and South Lebanon. The Mount Lebanon and Anti-Lebanon Chains take over $73 \%$ of the total mountainous area in which the majority of Crocus and Romulea of the Iridaceae family grow (Figure 1).

The phytogeography of the novel fifteen Varieties and Subspecies of the discovered Crocus baalbekensis is attributed to the climate, habitat, and location of two emblematic Mediterranean Lebanese territories in Beqaa plain and Anti-Lebanon Range. Beqaa is a plateau that splits both of Mount Lebanon and Anti- Lebanon ranges. It drapes an 8-12 km wide prolific plain and covers a range of approximately $120 \mathrm{~km}$ from North to South. The Anti-Lebanon Range overlays the Lebanese Syrian borders and reaches its highest point at 2,600 m called Tallat Moussa. The downhills are generally thinner in comparison to Mount Lebanon. The southern divisions of the Anti-Lebanon range incorporate Jabal el Cheikh (Mount Hermon) that encloses rainwater and reallocates water into three minimal central watersheds all over Lebanon, Syria, and Palestine (Figure 1)., ${ }^{2,8}$

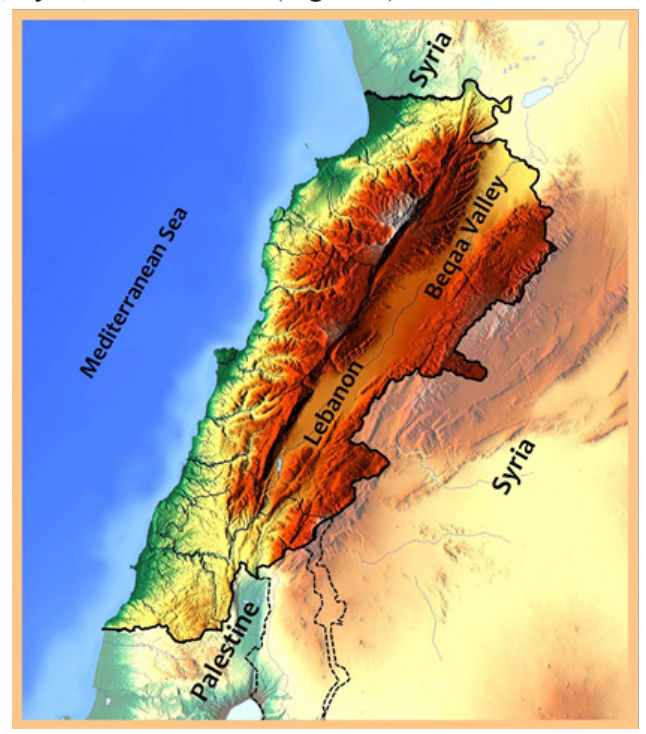

Figure I Map of Beqaa plain and Anti-Lebanon Range. 
The plant family Iridaceae is in order of Asparagales, which is named by a reference to Irises, meaning a rainbow that signifies a range of colors. Ninthytwo (66 accepted) genera with a total of 2244 species exist worldwide. ${ }^{8-10}$

The genus Crocus Linnaeus belongs to the gigantic family of Iridaceae and considered as a scientifically challenging genus. The genus is designated by its complex and stylish flowers. The origin of the name Crocus is Latin "crocatus" which means yellow saffron. Crocus taxa occupy a central place among the geophyte plants. ${ }^{11-14}$ Crocus is an important plant used since thousands of years ${ }^{14}$ whereby it owes to its high demand in perfumery, dye, flavoring and pharmaceutical industries. ${ }^{15}$ It is also used in some countries as a spice used in cooking and as a basic ingredient in making cheese. The extract of Crocus taxa has antimutagenic, antitumor, and cytototic activities. It is recently used for treating gut diseases, joint pains, Behçet and cancer. It was also used in Greek and Arabic medicine long time ago as a treatment for depression. ${ }^{8,15,16}$

Phytogeographically, most Crocus species belong to and are spread in the Mediterranean floristic basin comprising (Palestine, Turkey, Lebanon, Cyprus, Syria, Jordan and), South Western Europe, SouthWestern parts of Asia, Western part of China and Irano-Turanian phytochorion. ${ }^{17-21}$ Genus Crocus (Iridaceae) includes more than 235 taxa ${ }^{22}$ about 222 species, and 97 subspecies $^{23}$ distributed mainly in the Mediterranean territory.The most fundamental monographic treatments of the genus Crocus Linnaeus (1753:36) was published by Mathew (1982), "A Revision of the Genus Crocus", in which it was divided into two subgenera, two sections and 15 series. ${ }^{24}$ The Genus crocus is problematic systematically. ${ }^{25}$ Taxonomically, the genus is currently complicated, as e.g. a lot of the newly described taxa are not determined to any series. Furthermore, contemporary phylogenetic analyses proved some units within the genus Crocus to be para- or polyphyletic even at infra-specific level. $8,26,27$

Few are the scientists that operated on the Lebanese flora (Tohme and Tohme, 2014; Mouterde,1983; Post and Dinsmore, 1932 and others) but they had cited the genus crocus overall. Pierre Edmond Boissier, a Swiss botanist, mentioned Crocus gaillardotii (Boiss.\&Blanche) Maw and Crocus hyemalis var. gaillardotii Boiss. \& Blanche Gard. Chron.

However, no one of the earlier scientists had made a specific specialized research on the Iridaceae family (Crocus, Iris, and Romulea) in Lebanon until the oncoming of Dr. Khodr Addam and Mr. Mounir Bou-Hamdan. The first published new species Crocus baalbekensis K. Addam \& M. Bou-Hamdan and its three forms was at April 2019. ${ }^{8}$ This handful research resulted the exploration of new world records that will be mentioned in this publication (Figure 2).

All the Lebanese existing Crocuses mentioned by scientists were: C. hyemalis Boiss. \& Blanche., Crocus aleppicus Baker, C. graveolens Boiss. \& Reut., C. kotschyanus K. Koch,C. pallasii subsp. pallasii., C. pallasii subsp.haussknechtii (Boiss. \& Reut. ex Maw) B.Mathew., C. ochroleucus Boiss. \& Gaill., C. vitellinus Wahlenb., C. thiebautii Mouterde, C. haussknechtii (Boiss. \& Reut. ex Maw) Boiss., C. cancellatus Herb.C. cancellatus subsp. damascenus (Herb.) B. Mathew. C. cancellstus damascenus (Herb.) Mont,C. cancellatus var. cilicius Maw. Crocus baalbekensis K. Addam \& M. Bou-Hamdan, Crocus baalbekensis f. assiensis K. Addam \& M. Bou- Hamdan, Crocus baalbekensis f. ornata K. Addam \& M. BouHamdan., Crocus baalbekensis f. bella K. Addam \& M. Bou-Hamdan (Figure 2). ${ }^{8,28-30}$

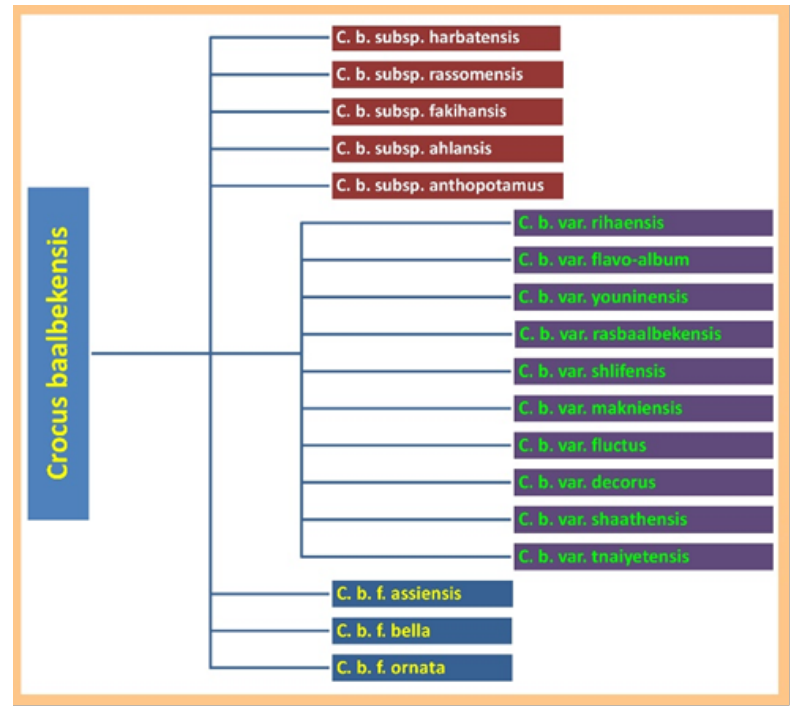

Figure 2 Classification of the C. baalbekensis family.

\section{The new-found varieties and subspecies are:}

1. Crocus baalbekensis subsp. ahlansis K. Addam \& M. BouHamda subsp. nov

2. Crocus baalbekensis subsp. anthopotamus K. Addam \& M. BouHamdan subsp. nov

3. Crocus baalbekensis subsp. fakihansis K. Addam \& M. BouHamdan subsp. nov

4. Crocus baalbekensis subsp. harbatansis K. Addam \& M. BouHamdan subsp. nov

5. Crocus baalbekensis subsp. rassomensis K. Addam \& M. BouHamdan subsp. nov

6. Crocus baalbekensis var. decorus K. Addam \& M. Bou-Hamdan var. nov

7. Crocus baalbekensis var. flavo-album K. Addam \& M. BouHamdan var. nov

8. Crocus baalbekensis var. fluctus K. Addam \& M. Bou-Hamdan var. nov

9. Crocus baalbekensis var. makniensis K. Addam \& M. BouHamdan var. nov

10. Crocus baalbekensis var. rasbaalbekensis K. Addam \& M. BouHamdan var. nov

11. Crocus baalbekensis var. rihaensis K. Addam \& M. BouHamdan var. nov

12. Crocus baalbekensis var. shaathensis K. Addam \& M. BouHamdan var. nov

13. Crocus baalbekensis var. shlifensis K. Addam \& M. BouHamdan var. nov

14. Crocus baalbekensis var. tnaiyetensis K. Addam \& M. BouHamdan var. nov

15. Crocus baalbekensis var. youninensis K. Addam \& M. BouHamdan var. nov 


\section{Materials and methods}

Observations were grounded on fresh materials of all Varieties and Subspecies. Crocus taxa lost most of their diagnostic characteristics when dried. Therefore, we measured and evaluated all morphological characters from fresh forms. Their number ranges mostly from ten to more (Figure 3). They were observed in many villages in northern Baalbek (Figure 4). Morphological data on C. baalbekensis were gathered from the type locality (Ras Baalbek, Harbata, Makneh, Fakiha, Ain Ahla (Shaath), Younine, Riha, Shaath, Shlifa, Tnaiyet el ras, Baalbek District). During our 22 years of field work, we found and registered all the species of crocus that were mentioned to exist in Lebanon. The new described Varieties and Subspecies were observed during our several fieldtrips between 2017-2019. They were discovered and pictured for the first time in 17/XII /2017 by Mr. Mounir Bou-Hamdan.

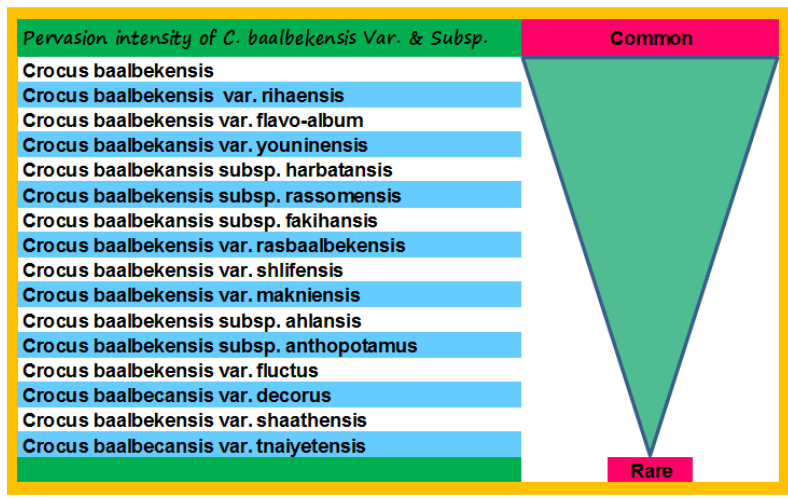

Figure 3 Pervasion intensity levels of C. baalbekensis Var. \& Subsp.

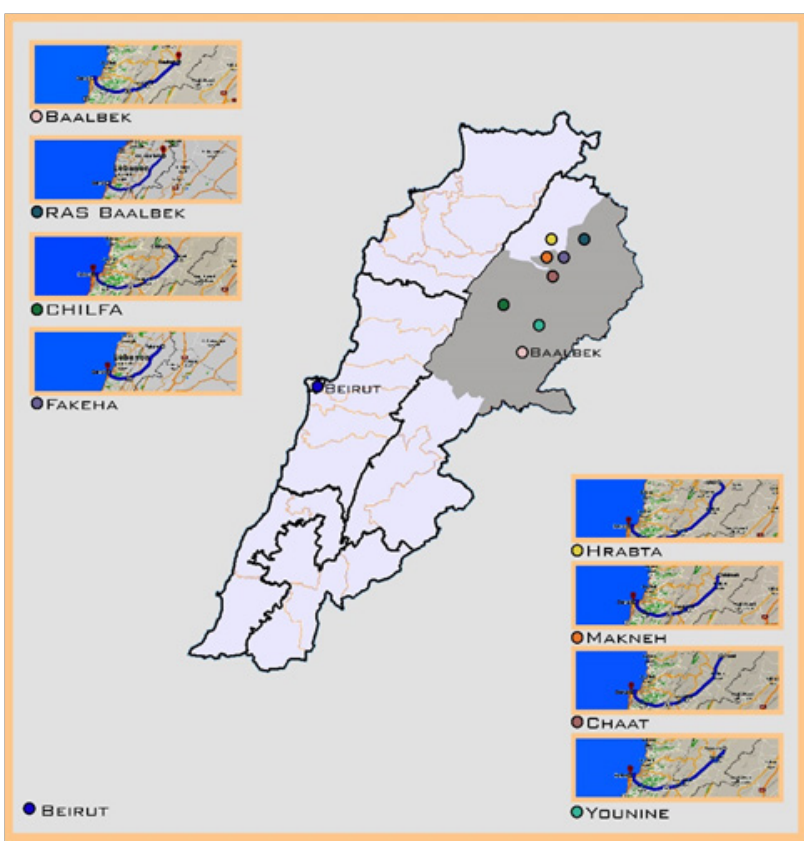

Figure 4 Location of $C$. baalbekensis varieties and Subspecies.

\section{Results and discussion}

\section{Description of Crocus baalbekensis K. Addam \& M.} Bou-Hamdan

"Flower 1-6, (30-40) mm tall, white, opened wide with star like form, extremely fragrant (Fresia smell), and attractive to bees. Corm oblong conical about $18-26 \mathrm{mmx} 14-20 \mathrm{~mm}$ in diameter, corm tunic is of 4-10 layers of brown extended neck 10-20mm, great build-up of old tunics, coarse parallel fibers, not glued together, with cross-links and become thinner in the inner layers, stolon forming corms are absent, roots are white-creamy and branched, leaves (present at flowering) $4-12,50-110 \mathrm{mmx} 0.8-1.2 \mathrm{~mm}$, green, looking glabrous but in fact the two faces of the leaf have sporadic micro appendages chiefly on the edges, and very fine fluff on the upper face, white stripe about $1 / 4$ of leaf keel, rarely narrower, leaf cross-section is T-shape, central nearly trapezoidal keel and 2 average length lateral arms with their margins recurved towards the keel, keel has a small notch in the middle and lamina is wider than the leaf keel but less than twice, spathe, 3-4, membranous white to pale yellow pipe with diagonal head shape, each perianth tube is covered by two inner membranous white spathe that reach the perianth throat, perianth tube is white $=1.2 \ldots 1.6 \mathrm{As}$ long as the perianth segments. The perianth segments are $20-26 \mathrm{~mm}$ tall of white flower, 6 lanceolate tepals, acute tepal of apex shape, deep yellow throat, very fragrant mostly in the evening, outer perianth segment, 3, oblanceolate, $20-26 \mathrm{~mm} \times 4.2-5.4 \mathrm{~mm}$, abaxial side is colored by yellow till one third of the tepal, mottled by dark blueviolet, three stripes (rarely one) with dark violet veins (sometimes mottled by pale yellow between the violet veins) starts from the base of the tepal and ends at its apex, all segment heads are blotched by dark blue-violet, adaxial side is white with deep yellow area that covers approximately one third of segment bottom. Inner perianth segment, 3 , white oblanceolate segments $18-24 \mathrm{~mm} \times 5-7 \mathrm{~mm}$, deep yellow area covers approximately one third of segment bottom in both sides, one third of the abaxial side of the of segment bottom is covered by deep blue - violet lanceolate strip with branching veins, throat, deep yellow color covers one third of the length of the perianth segments (the colors and the strips on the tepal disappear when they reach the tube. The tube that lies under the parianth has a pure white color), filament, 3, deep yellow, (papillose to densely pubescent especially towards basis) covered by micro glandular appendages $4-7 \mathrm{mmx} 0.6-$ $0.8 \mathrm{~mm}$ (diameter), anther, 3, 7-10 mmx1.2-1.8mm, wide, arrow shape, longitudinally striped in black and yellow, style (at perianth segments) 1 , deep yellow to orange, $14-22 \mathrm{mmx} 0.4-0.8 \mathrm{~mm}$ (sometimes striped by thinner black lines), divided to 3 stigmas, equal or longer than the stamen, stigma (each one) is branched to 3-6 short strands, pollen yellowish orange, seeds, 2.8-3.6mmx2.2-2.6mm (diameter), ellipsoid, small, black, large head, small pointed tail and coarse surface" (Figures 5-8).

\section{Description of the new varieties and subspecies. (All the measures are done on the holotypes)}

All the new discovered varieties and subspecies display Crocus baalbekensis K. Addam \& M. Bou-Hamdan but differ in the following specifications:

\section{Crocus baalbekensis subsp. ahlansis K. Addam \& $\mathrm{M}$. Bou-Hamda subsp. nov}

Leaves are $110-150 \mathrm{~mm}$ length, $1.4-2 \mathrm{~mm}$ width, appearing with the flowers, different cross section than C. baalbekensis. Corm tunic, extended neck $20-40 \mathrm{~mm}$. Spathe membranous light yellow to white pipes with diagonal head shape. Perianth tube, from the ovary and up until 88 to $92 \%$ of the tube length is white, the rest colored by the colors of perianth segments. Outer Perianth Segment, 3 white lanceolate segments $6-7.5 \mathrm{~mm}$ width, deep to light yellow area covers one third of segment length on both faces of the bottom, and a wide strip of dark blue-violet veins on the outer face covers almost all segment length with white to light yellow side edges. Inner 
Perianth Segment, 3 white lanceolate segments, deep to light yellow area covers one third of segment length on both faces of the bottom, spearhead strip of dark blue-violet veins become obtuse in the top, on the external face on bottom quarter of the segment length. Stigma, each one branching into 2-4 short strands (Figures 6-8).

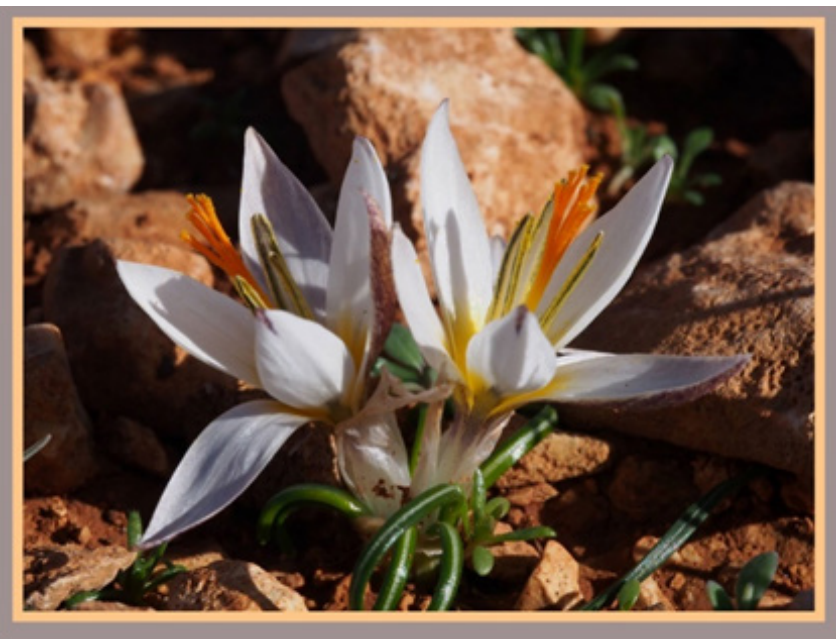

Figure 5 Crocus baalbekensis in flower.

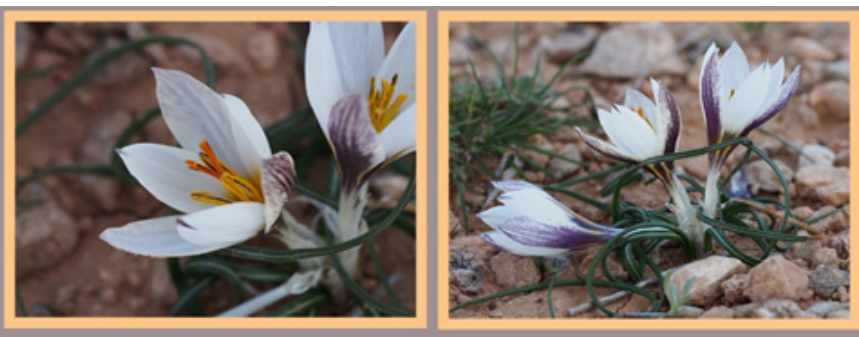

Figure 6 C. b subsp. ahlansis in flower.

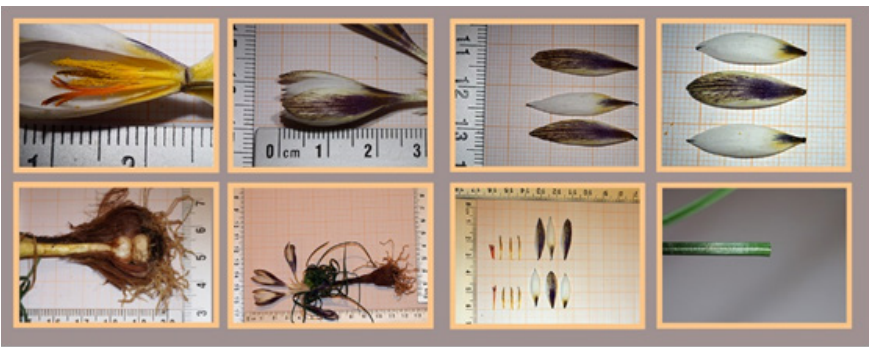

Figure 7 C. b subsp. ahlansis flower parts variations.

\section{Crocus baalbekensis subsp. anthopotamus K.Addam \& M. Bou-Hamdan subsp. nov}

Leave with different cross section than C. baalbekensis. Spathe, membranous light yellow (the outer one) to white pipes with diagonal head shape. Perianth Tube, 3 quarters of the bottom are white, the last quarter until the perianth segment is colored by yellow. Outer Perianth Segment, 3 white lanceolate segments, with a light to deep yellow area covers less than one third of segment length on both faces of the bottom and can be tagged by one thin middle spearhead strip of green to black veins on the external face on bottom third of segment length Inner Perianth Segment, 3 white lanceolate segments, with a light to deep yellow area covers the bottom third of segment length on both faces, and not tagged by any colored shape on the outer face. Anther, $0.6-1.2 \mathrm{~mm}$ width (Figures 8-10).

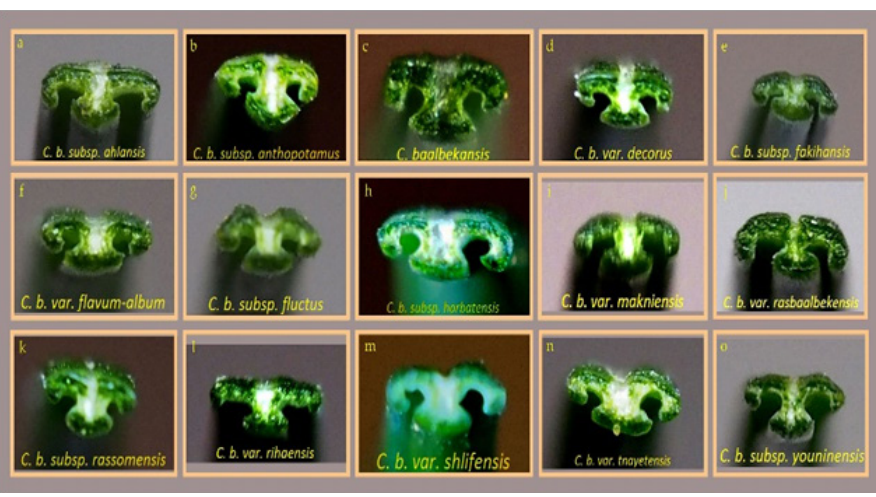

Figure 8 Leaves' transverse dissection of Varieties. \& Subspecies.

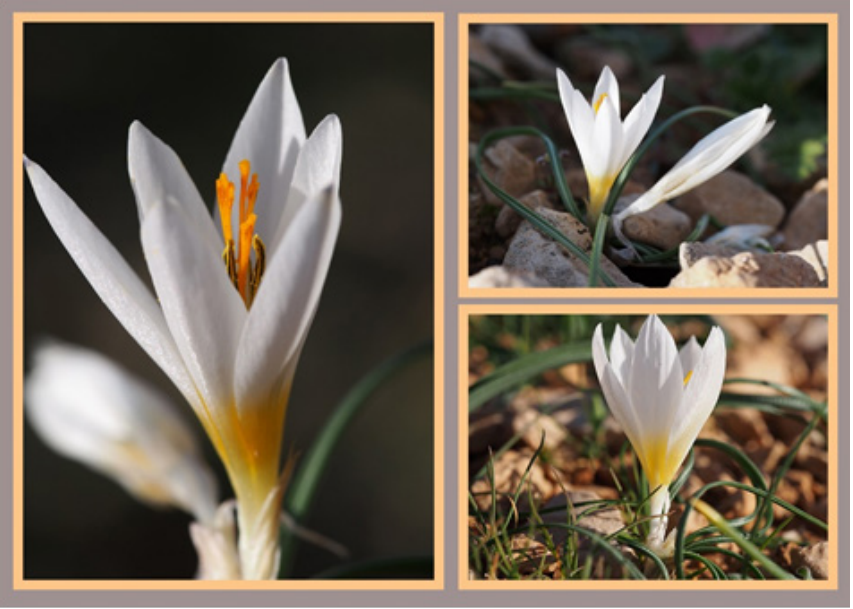

Figure 9 C. b. subsp. anthopotamus in flower.

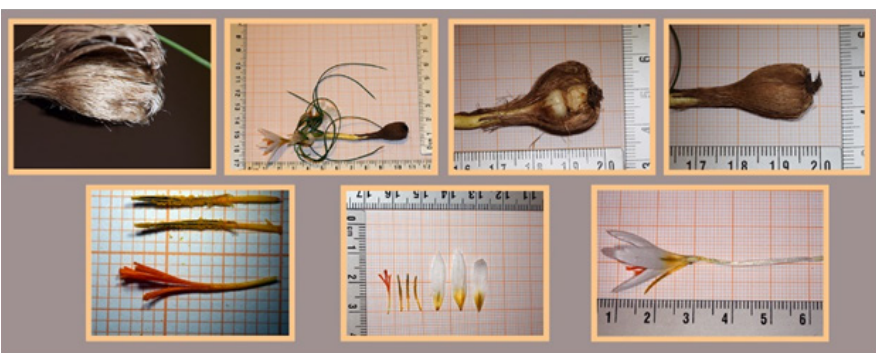

Figure I 0 C. b subsp. anthopotamus flower parts variations.

Crocus baalbekensis subsp. fakihansis K. Addam \& $\mathbf{M}$. Bou-Hamdan subsp. nov

Corm tunic, silky reddish brown coarse parallel fibers. Spathe has membranous pale yellow to yellow pipes. Perianth Tube, white to pale yellow and $=1.8-2.2$ of Perianth Segment. Outer Perianth Segment: 3 white lanceolate segments, with a light orange area covers $<1 / 3$ of segment length on both faces of the bottom, and a spiny form strip of black veins on the outer face on the bottom half of segment length continue by a middle yellow vein to the segment head. Inner Perianth Segment: 3 white lanceolate segments, with a light orange area covers $<1 / 3$ of segment length on both faces of the bottom, and a middle strip of dense black veins on $<1 / 3$ the outer face on the bottom of segment length. Throat: Light orange color covers less than one third of the perianth segments. Filament $0.8-1 \mathrm{~mm}$ diameter, light orange, covered by micro glandular appendages. Style (at perianth segments), orange divided to 3 stigmas (Figure 8) (Figure 11) (Figure 12). 

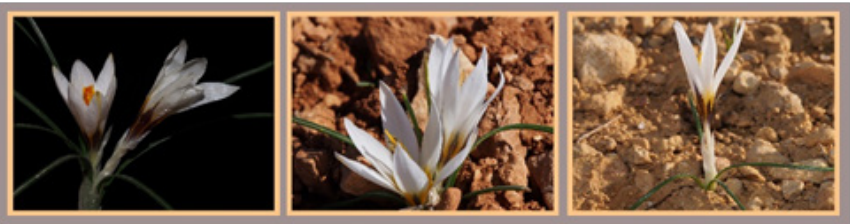

Figure I I C. b. subsp. fakihansis in flower.

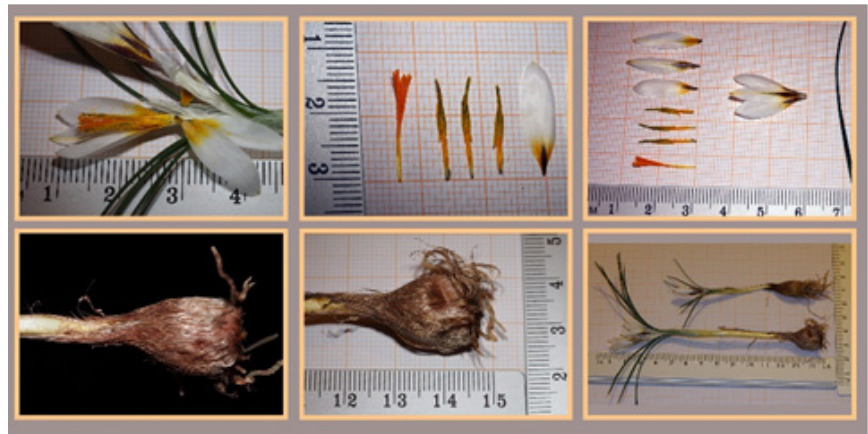

Figure 12 C. b subsp. fakihansis flower parts variations.

\section{Crocus baalbekensis subsp. harbatansis K.Addam \& M.} Bou-Hamdan subsp. nov

Outer Perianth Segment, 3 white lanceolate segments are colored yellow mottled by dark blue - violet with middle strip of dark veins continue to the segment head from outside can be wider from the base to more than the half of segment length. From inside white with a deep yellow area covers approximately one third of segment bottom.

Inner Perianth Segment 3 white lanceolate segments, deep yellow area covers approx. one third of segment bottom in both faces, and with lanceolate stripe of black veins on one third of segment bottom from outside. Anther, wide width $2-2.2 \mathrm{~mm}$. Style (at perianth segments) 11-16mm (Figure 8) (Figure 13) (Figure 14).
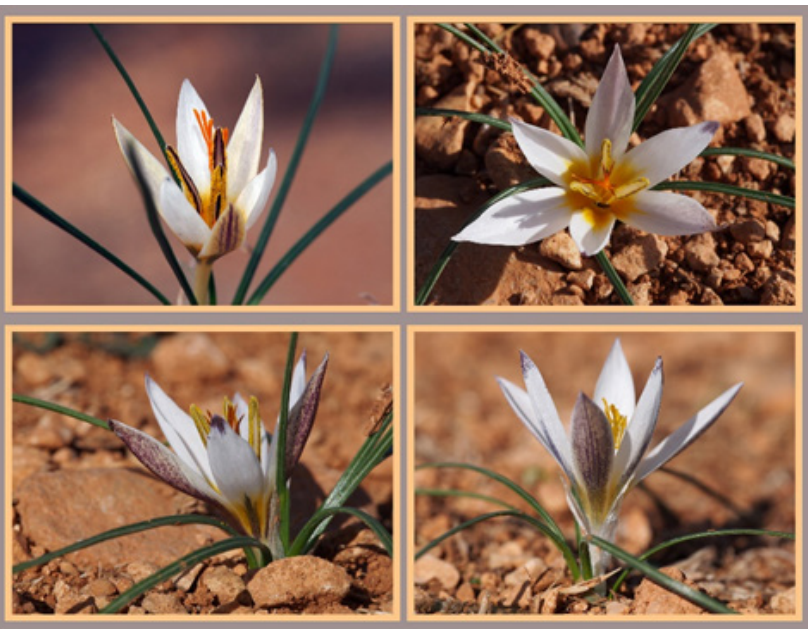

Figure 13 C. b. subsp. harbatansis in flower

\section{Crocus baalbekensis subsp. rassomensis K. Addam \& M. Bou-Hamdan subsp. nov}

Corm, conical leaves appearing with the flowers having different cross section than C. baalbekensis. Perianth segments, white flower with 6 lanceolate tepals with light to deep yellow throat. Outer Perianth Segment 3 white lanceolate segments, 6-7.5mm width, light to deep yellow area covers less than one third of segment length on both faces of the bottom, and one middle spearhead strip of dark blue-violet veins on the external face that reaches the bottom half of segment length. Inner Perianth Segment 3 white lanceolate segments, with a light to deep yellow area covers less than the bottom third of segment length on both faces, and a spearhead strip of dark blue-violet veins become obtuse in the top, on the external face on bottom quarter of the segment length. Style (at perianth segments): Deep yellow to orange not striped by thinner black lines, divided to 3 stigmas. Stigma, each one branching into 3-6 long strands with $1-1.5 \mathrm{~mm}$ of black tips (black ends) (Figure 8) (Figure 15) (Figure 16).

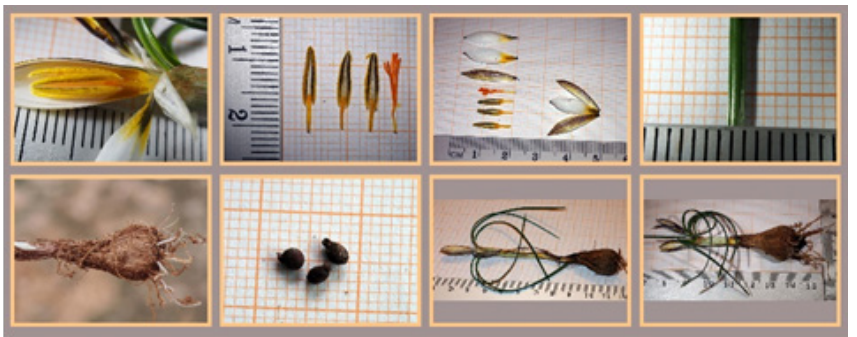

Figure I 4 C. b subsp. harbatansis flower parts variations

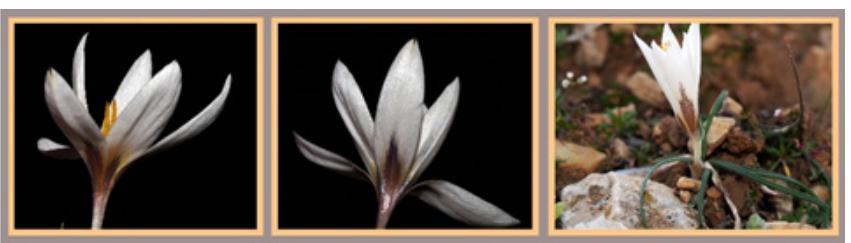

Figure 15 C. b. subsp. rassomensis in flower.

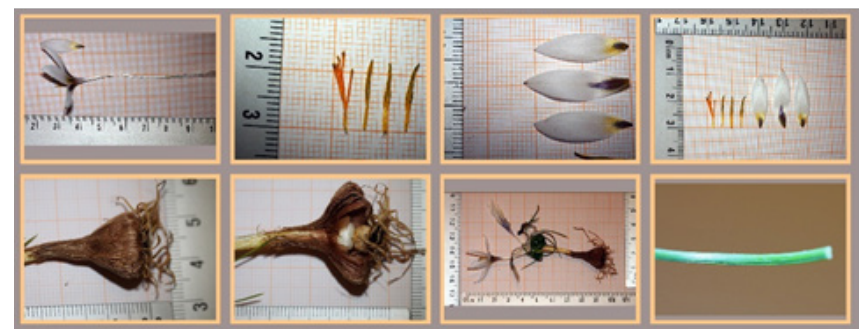

Figure $16 \mathrm{C}$. b subsp. rassomensis flower parts variations.

\section{Crocus baalbekensis var. decorus K.Addam \& M. Bou- Hamdan var. nov}

Flower 20-30mm. Leaves 1.2-1.8mm width. Spathe, membranous pale yellow to yellow pipes with diagonal head shape, the inners are white. Reddish brown coarse parallel fibers, in the form of alternating tufts glued and not glued together with cross-links and become thinner in the inner layers. Perianth tube, 4 fifths of the bottom are white, the last fifth till the perianth segment is mottled by blue violet, perianth Tube $=0.9-1.3$ of Perianth segment. Outer Perianth Segment 5-6, 3 white lanceolate segments, with a deep yellow area covers the lower third of segment length on both faces with cotton fur form on the inner lower third, and a large strip of blue-violet ( $\mathrm{V}$ form mottled veins) on the outer face on all segment length with a yellow middle ribbon, other form with deep yellow background under the veins makes petal looks light brown. Inner Perianth Segment 4-5, 3 white lanceolate segments, with a deep yellow area covers the lower third of segment length on both faces with cotton fur form on the inner lower third, and a middle strip of blue-violet mottled veins on the lower third of segment length. Style (at perianth segments), each one branching into 3-6 medium to short strands Shorter to equal to the stamen (Figure 8) (Figure 17) (Figure 18). 


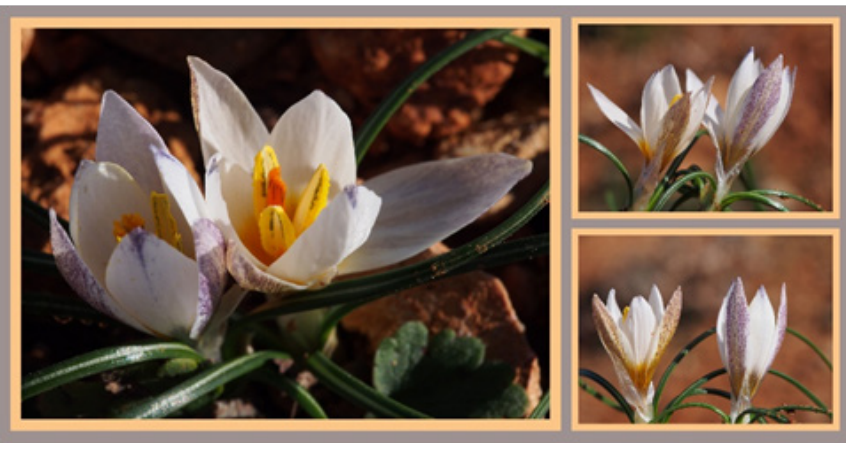

Figure 17 C.b. var. decorus in flower.

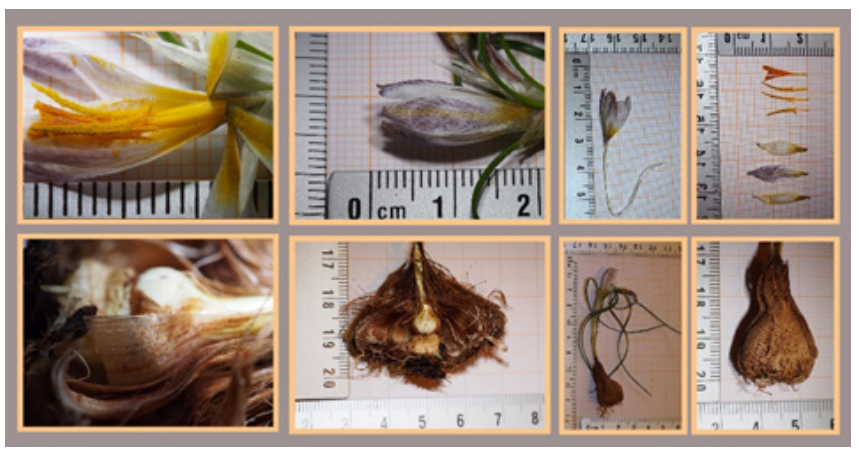

Figure 18 C. b var. decorus flower parts variations.

Crocus baalbekensis var. flavo-album K. Addam \& $\mathbf{M}$. Bou-Hamdan var. nov

The brown to brown-reddish coarse parallel fibers and fiber tufts are glued together in some places and in others are not in the outer layer of the same Corm tunic, with cross-links that become thinner in the inner layers. Spathe, membranous light yellow (the outer one) to white pipes with diagonal head shape. Perianth tube $=1.5$ to 1.8 of Perianth Segment 4 fifths of the bottom are white, the last fifth until the perianth segment is mottled by blue - violet. Outer Perianth Segment 3 white lanceolate segments, deep yellow area covers one third of segment length of the inner face at the bottom, and deep yellow middle spearhead strip covers more than 1 third of the bottom part of outer segment length that sometimes continue to the top mottled by blue-violet until the tepal head. Inner Perianth Segment, 3 white lanceolate segments with a deep yellow area covers one third of the segment faces at the bottom and can be mottled by blue violet on the outer face. Filament $4-8 \mathrm{~mm}$. Anther $7-12 \mathrm{~mm}$ and $1.5-2 \mathrm{~mm}$ width. Style (at perianth segments) $10-16 \mathrm{~mm}$, shorter or (sometimes) little bit longer than the stamen (Figure 8) (Figure 19) (Figure 20).

\section{Crocus baalbekensis var. fluctus K. Addam \& M. Bou- Hamdan var. nov}

Corm tunic, wavy reddish brown coarse parallel fibers glued together with cross-links; in the form of tufts, become thinner in the inner layers. Leaves, $120-160 \mathrm{~mm}$, appearing with the flowers, have different cross section than C. baalbekensis. Spathe, membranous pale yellow to yellow pipes with diagonal head shape, the inners are white. Perianth Tube $=1.6-2$ of Perianth Segment. Outer Perianth Segment, 3 white lanceolate segments, with deep yellow area covers $<1 / 3$ of segment length on both faces of the bottom, and an obtuse strip of dark-blue dense veins on the outer face on the lower half of segment length continuing as mottled area to the segment head on a light yellow background. Inner Perianth Segment, 3 white lanceolate segments, with a deep yellow area covers $<1 / 3$ of segment length on both faces of its bottom, and a middle thin lanceolate strip of dark blue-violet dense veins on $<1 / 4$ of the outer face on the bottom of segment length. Filament, 0.6-0.8mm diameter (Figure 8) (Figure 21) (Figure 22).

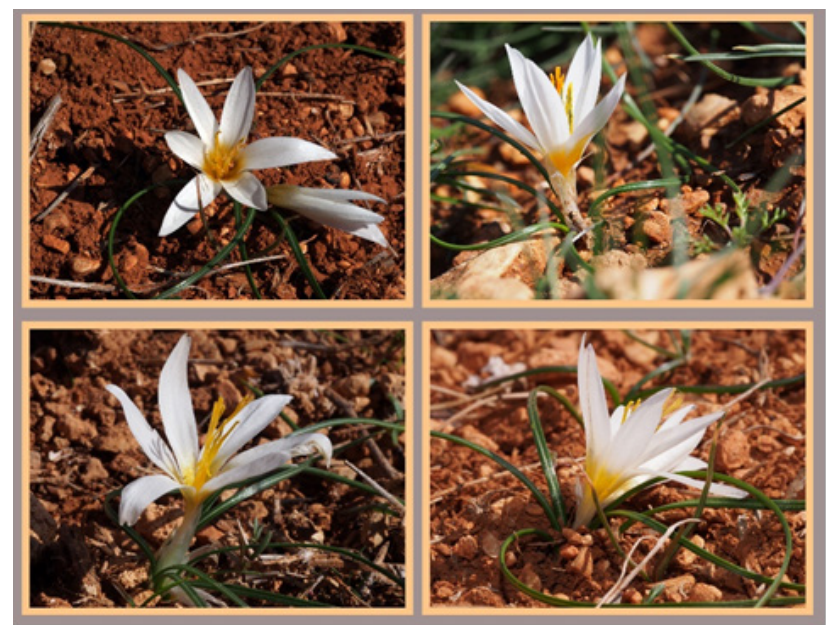

Figure 19 C. b var. flavo-album in flower.

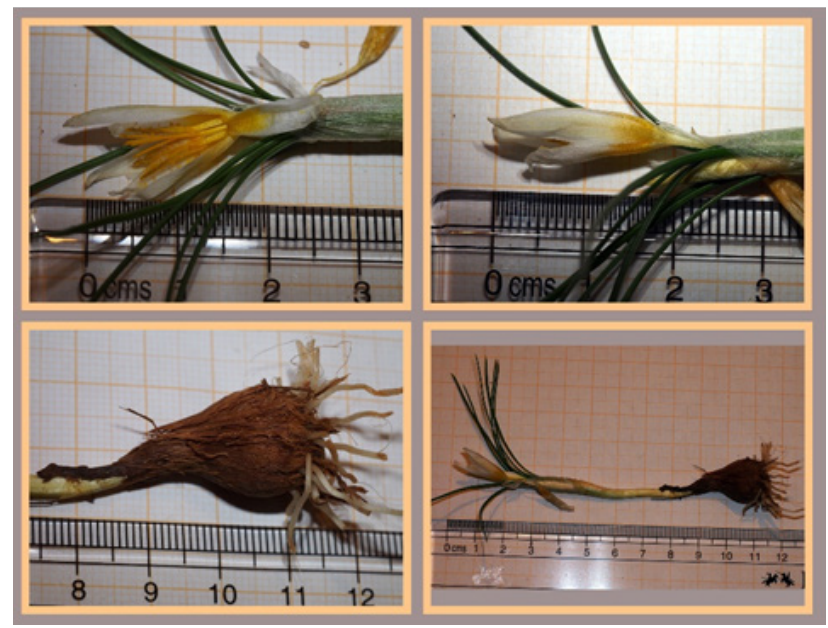

Figure 20 C. b var. flavo-album flower parts variations.

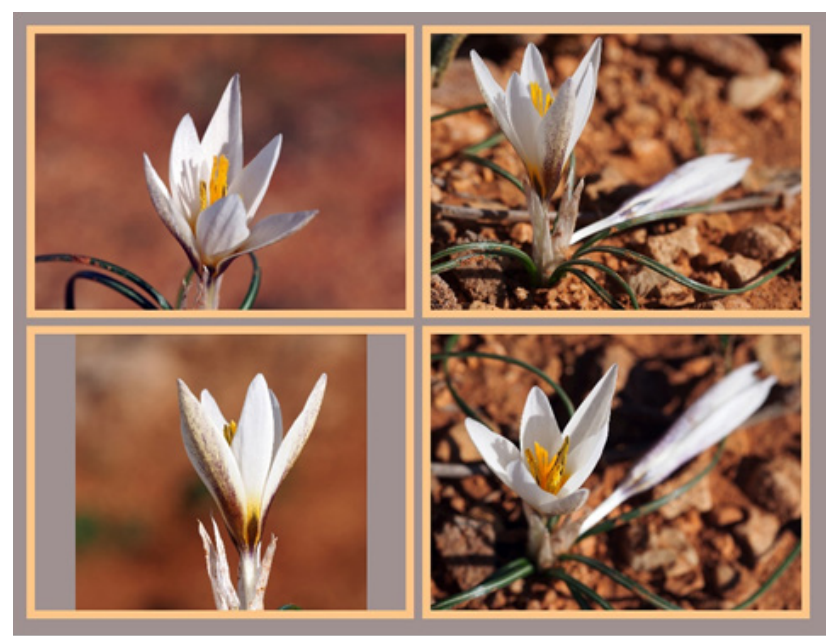

Figure 2 I C. b var. fluctus in flower. 


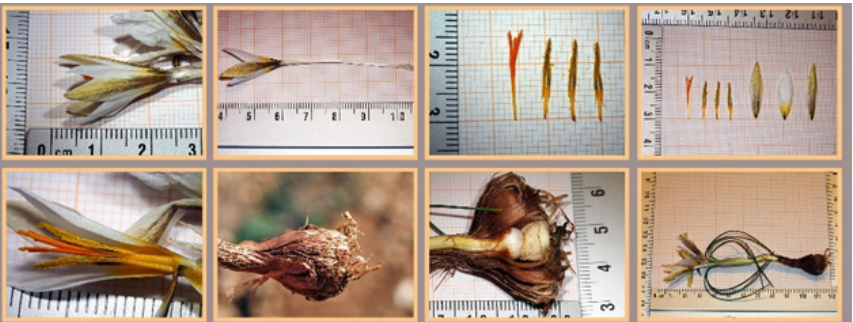

Figure 22 C. b var. fluctus flower parts variations.

Crocus baalbekensis var. makniensis K. Addam \& M. Bou-Hamdan var. nov

Corm, oval elongated, often with a swelling on the extended corm tunic to the neck with a diameter $6-10 \mathrm{~mm}$ and height $22-30 \mathrm{~mm}$. Corm tunic, reddish brown with parallel coarse fibrous glued together with cross-links. Leaves, with a different cross section than those of $\mathrm{C}$. baalbekensis. Parianth tube length $=0.9-1.3$ of perianth segment. Perianth segment, 16-20mm. Outer Perianth Segment, strip of 3 dark blue-black veins as spearhead shape on the outer face from the bottom to the half of segment length with a short line on the segment head. Inner Perianth Segment, strip of dark blue-black veins on the external face from the bottom to one third of segment length. Throat, deep yellow color covers less than one third of the length of the perianth segments. Anther, $1-1.25 \mathrm{~mm}$ width. Filaments are $3-4 \mathrm{~mm}$, style diameter (at perianth segments, often longer than the stamen) 0.2$0.3 \mathrm{~mm}$ (Figure 8) (Figure 23) (Figure 24).

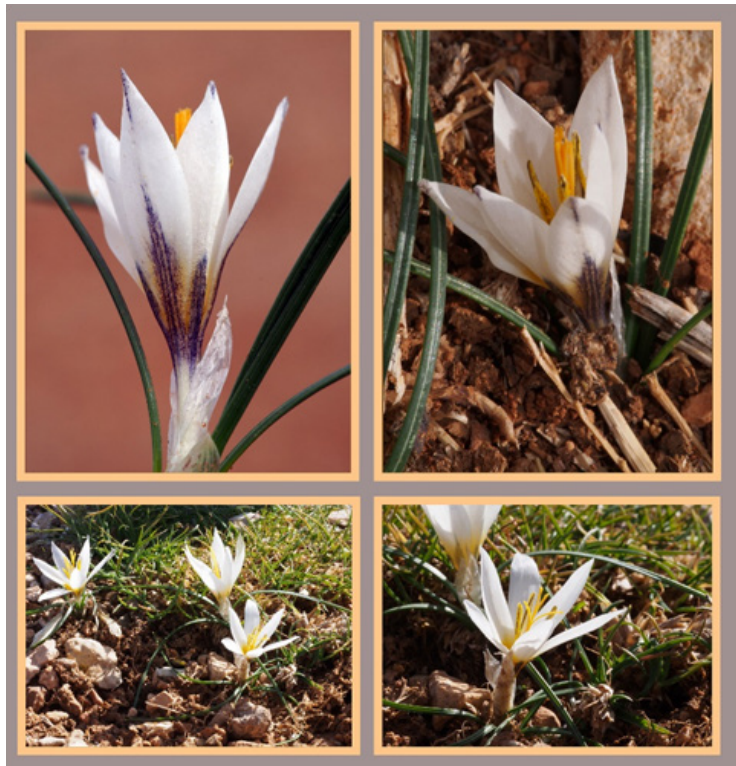

Figure 23 C. b var. makniensis in flower.

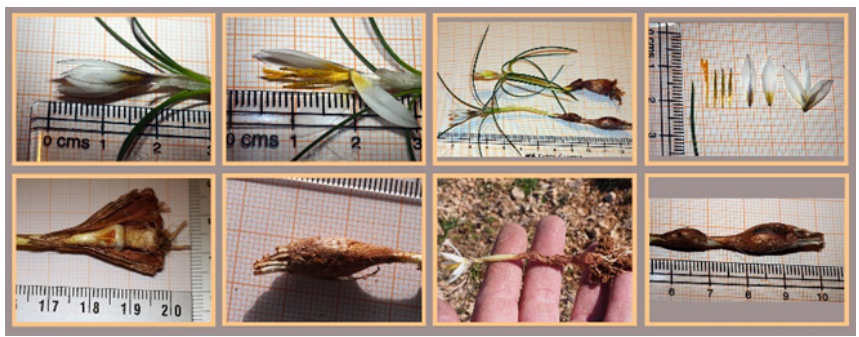

Figure 24 C. b var. makniensis flower parts variations.

\section{Crocus baalbekensis var. rasbaalbekensis K. Addam \& M. Bou-Hamdan var. nov}

Corm tunic, brown coarse parallel fibers glued together with cross-links, becomes thinner in the inner layers. Leaves, $1.2-1.6 \mathrm{~mm}$ width, appearing with the flowers, with a different cross section than C. baalbekensis. Spathe, membranous light yellow (the outer one) to white pipes. Perianth tube, 2 thirds of the bottom have white color while the last third till the perianth segment is colored by red or blue violet. Outer Perianth Segment, 3 white lanceolate segments, deep yellow area covers one third of segment length on the bottom of inner face, and a strip of red veins (fuchsia to red wine color) on a base of white to light yellow color on the outer face of whole segment area. Anther, 0.8-1.4mm (Figure 8) (Figure 25) (Figure 26).

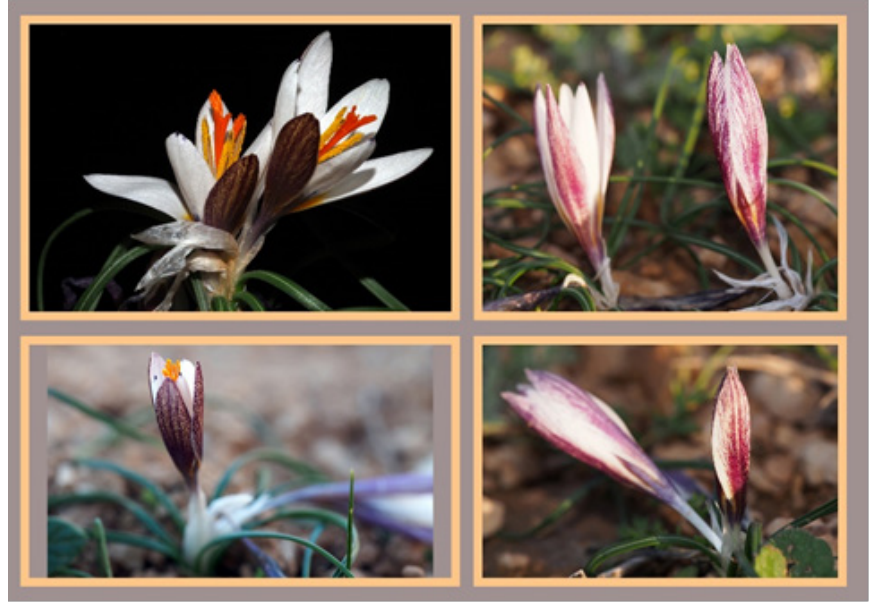

Figure 25 C. b var. rasbaalbekensis in flower.

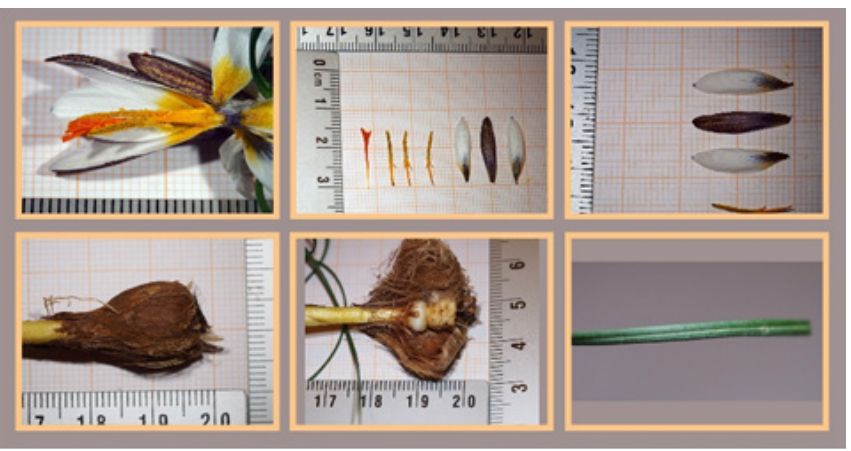

Figure 26 C. b var. rasbaalbekensis flower parts variations.

\section{Crocus baalbekensis var. rihaensis K.Addam \& M. Bou- Hamdan var. nov}

Corm is $20-40 \mathrm{~mm}$, diameter $16-24 \mathrm{~mm}$. Leaves $1.2-1.6 \mathrm{~mm}$ width with a different cross section than C. baalbekensis Outer Perianth Segment, colored by light yellow mottled with blue with white side edges and deep yellow mottled with blue covers the bottom quarter from outside; from inside white with a deep yellow area covers the bottom quarter. Inner Perianth Segment, deep yellow area covers the bottom quarter on both faces with a short middle strip of light blueviolet veins from outside. Throat, deep yellow color that covers the bottom quarter of the perianth segments' length and white mottled with blue in the connection area with the perianth tube. Anther, 0.7$1.5 \mathrm{~mm}$ width (Figure 8) (Figure 27) (Figure 28). 

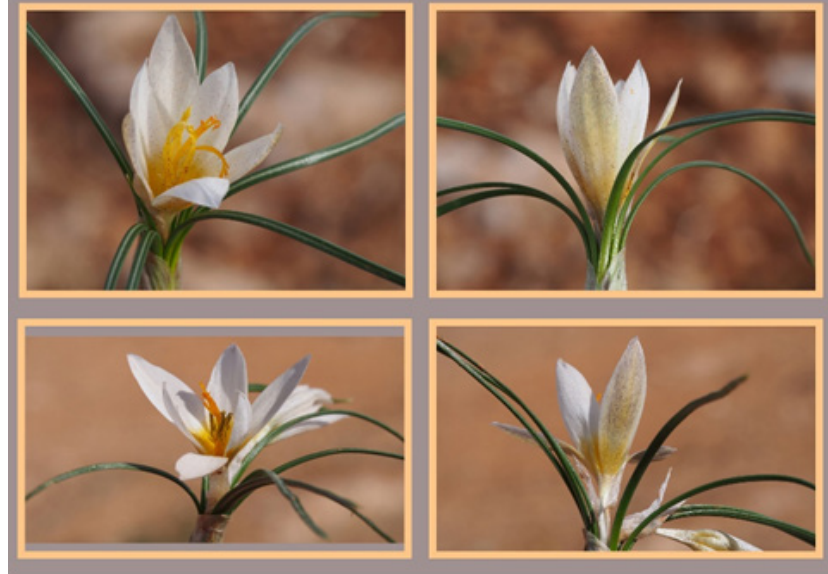

Figure 27 C. b var. rihaensis in flower.

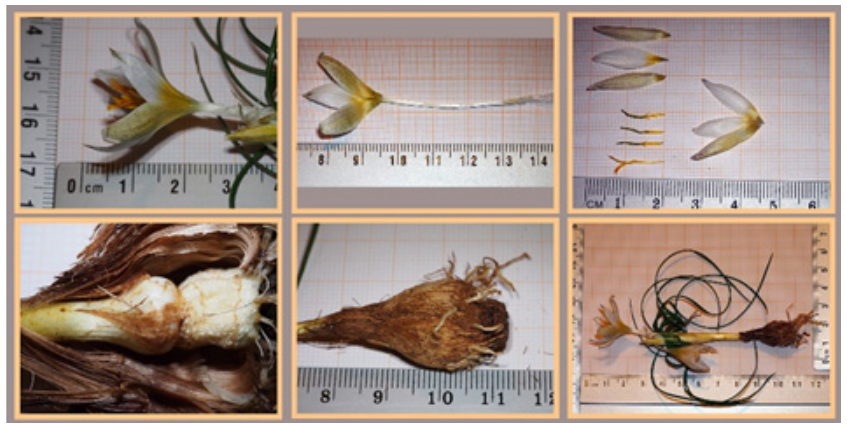

Figure 28 C. b var. rihaensis flower parts variations.

\section{Crocus baalbekensis var. shaathensis K. Addam \& M. Bou-Hamdan var. nov}

The brown to brown-reddish coarse parallel fibers and fiber tufts are glued together in some places and in others are not in the same Corm tunic. Spathe, membranous pale yellow to yellow pipes. Perianth tube is pale yellow. Perianth segments $16-20 \mathrm{~mm}$. Outer Perianth Segment, yellow middle strip on the external face (Rarely the external face is mottled with blur blue fine spots). Inner Perianth Segment, 3 white lanceolate segments (14-18mm), with a deep yellow area covers one third of segment length on both faces of the bottom. Filament 3-4mm, diameter 0.4-0.6mm. Another has 0.9-1.1mm width. Style (at perianth segments): $8-10 \mathrm{~mm}$ length, shorter or equal to the stamen ends) (Figure 8) (Figure 29) (Figure 30).
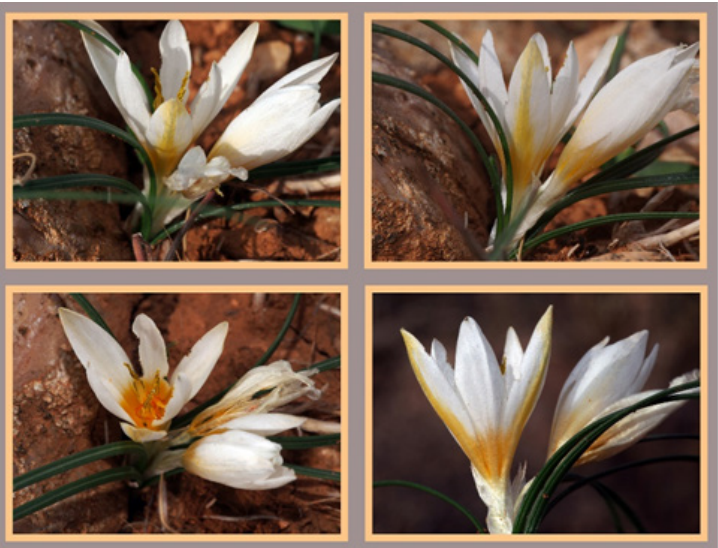

Figure 29 C. b var. shaathensis in flower.

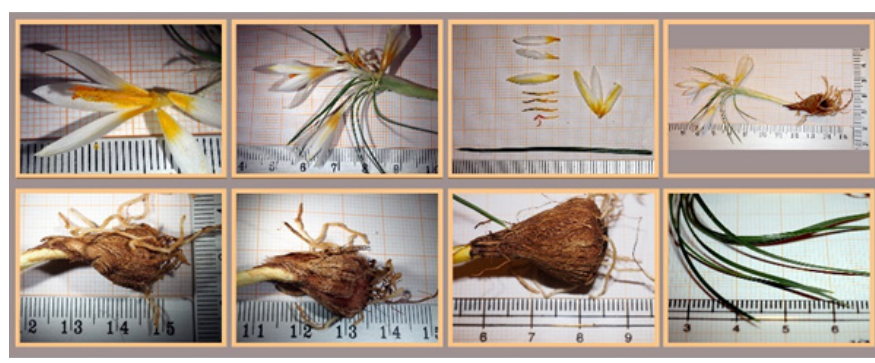

Figure $30 \mathrm{C}$. b var. shaathensis flower parts variations.

\section{Crocus baalbekensis var. shlifensis K.Addam \& M. Bou- Hamdan var. nov}

Rain fall 400-600ml

Flower $25-35 \mathrm{~mm}$ height. Corm tunic, Brown coarse parallel fibers glued together with cross-links, becomes thinner in the inner layers. Leaves $60-80 \mathrm{~mm}$, appearing with the flowers, with a different cross section than C. baalbekensis. Outer Perianth Segment 3 white lanceolate segments, with a deep yellow area covers one third of segment length on both faces of the bottom, and a wide strip of dark blue-violet veins at the middle of the external face of the whole segment length (sometimes mottled by pale yellow between the violet veins). Inner Perianth Segment, 3 white lanceolate segments, with a deep yellow area covers the bottom third of segment length on both faces, and a strip of dark blue-violet veins that become obtuse at the top, on the external face on bottom third of the segment length. Style (at perianth segments) Deep yellow to orange and not striped by thinner black lines, divided to 3 stigmas (Figure 8) (Figure 31) (Figure 32).

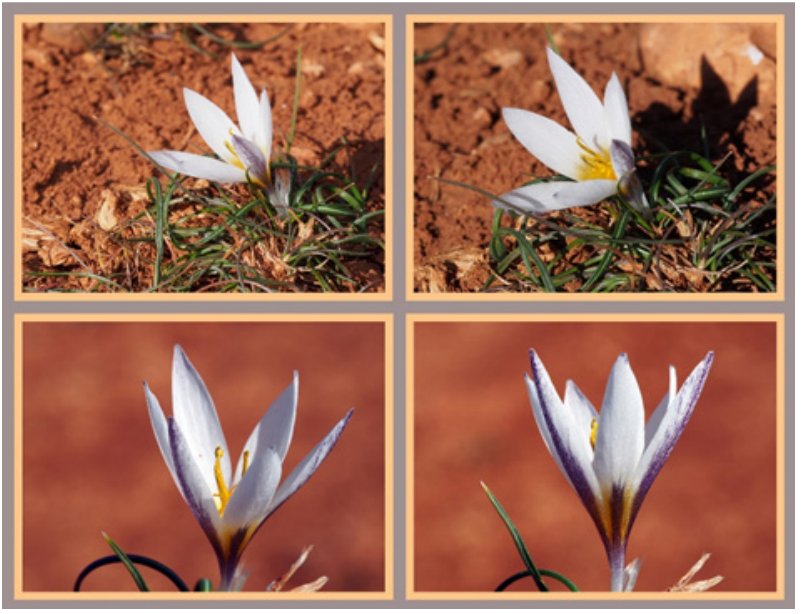

Figure 3 I C. b var. shlifensis in flower

\section{Crocus baalbekensis var. tnaiyetensis K. Addam \& $\mathbf{M}$. Bou-Hamdan var. nov}

Corm Tunic brown coarse parallel fibers glued together with cross-links, become thinner in the inner layers. Spathe: Membranous light yellow (the outer one) to white pipes. Leaves $40-60 \mathrm{~mm}$ with a different cross section than C. baalbekensis. Parianth tube length $=0.9-1.1$ of perianth segment. Outer Perianth Segment: 3 white lanceolate segments $5-7 \mathrm{~mm}$ width, light to deep yellow area covers one third (can be more) of segment length on both faces of the bottom, lanceolate strip (with obtuse head) of light blue-violet mottled veins on 
the bottom third of segment length gives a color like green olive. Inner Perianth Segment width: 6-8 mm: 3 white lanceolate segments, with a light to deep yellow area covers one third (can be more) of segment length on 2 faces of the bottom, lanceolate strip (with obtuse head) of light blue-violet mottled veins on the bottom quarter of segment length gives a color like green olive. Throat, light to deep yellow color covers one third of the length of the perianth segments. Filament $0.8-1 \mathrm{~mm}$ diameter, light to deep yellow, covered by micro glandular appendages. Another arrow shape, width $1-2 \mathrm{~mm}$ with middle white membranous area longitudinally striped in black and light yellow to white. Style (at perianth segments) $10-15 \mathrm{~mm}$, deep yellow to orange can be striped by thinner black lines, divided to 3 stigmas, equal or shorter than the stamen. Stigma, each one is branched into 2-3 short expanded strands (Figure 8) (Figure 33) (Figure 34).

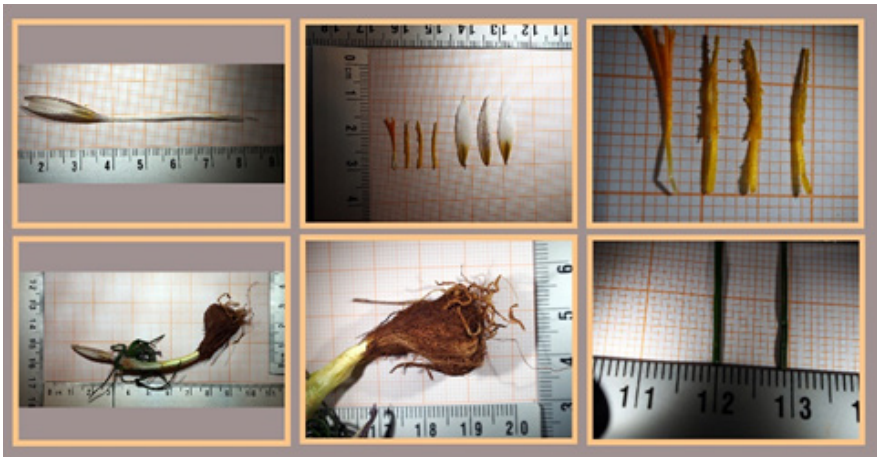

Figure 32 C. b var. shlifensis flower parts variations.

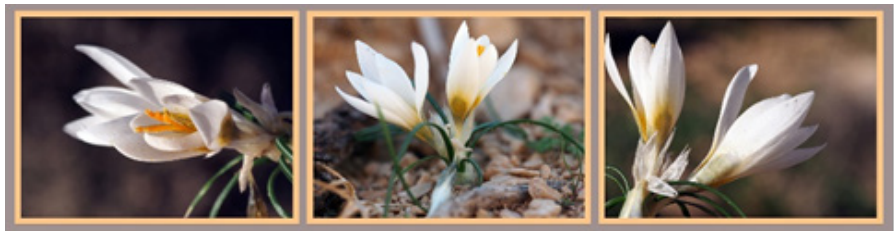

Figure 33 C. b var. tnaiyetensis in flower.

\section{Crocus baalbekensis var. youninensis K. Addam \& $\mathbf{M}$. Bou-Hamdan subsp. nov}

Flower is white semi-opened with waft scent. Corm tunic contains brown wavy coarse parallel fibers in the bottom with a cap of glued fibers covering the upper half of the corm and reaching the neck. Leaves' number is 6-12, 1-1.3 width, with a different cross section than C. baalbekensis. Tube length $=06-1$ of perianth segment. Perianth segments contains small pale-yellow throat. Outer Perianth Segment includes 3 white lanceolate segments, width $2.2-2.6 \mathrm{~mm}$, mottled with blue from outside, and pale yellow with blue covers the bottom third. From inside a pale-yellow color covers one third of the segment at the bottom. Inner Perianth Segment includes 3 white lanceolate segments; width $3.2-3.6 \mathrm{~mm}$, one-third is mottled with blue from outside as lanceolate dark area and a short blue line on the segment head. From inside a pale-yellow color covers one third of the segment at the bottom. Throat pale yellow color covers one third of the length of the perianth segments. Filament is pale yellow, covered by micro glandular appendages. Style (at perianth segments) is Pale yellow, divided to 3 wide stigmas and each one divided to thin strands (Figure 8) (Figure 35) (Figure 36)

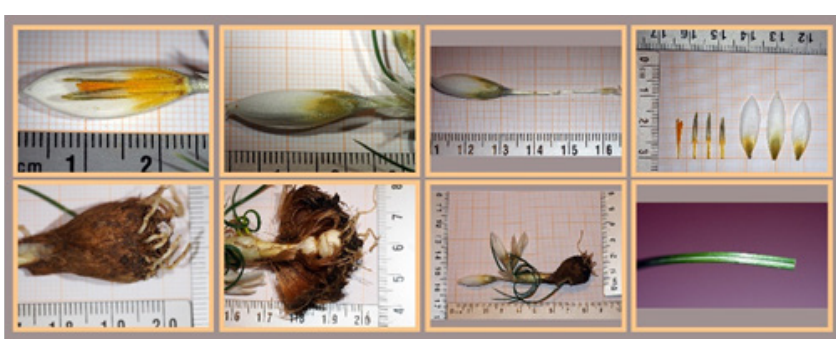

Figure 34 C. b var. tnaiyetensis flower parts variations.

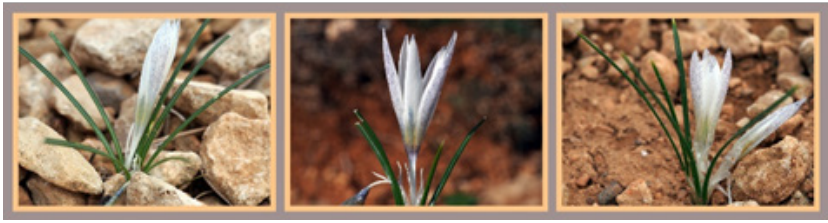

Figure 35 C. b var. youninensis in flower.

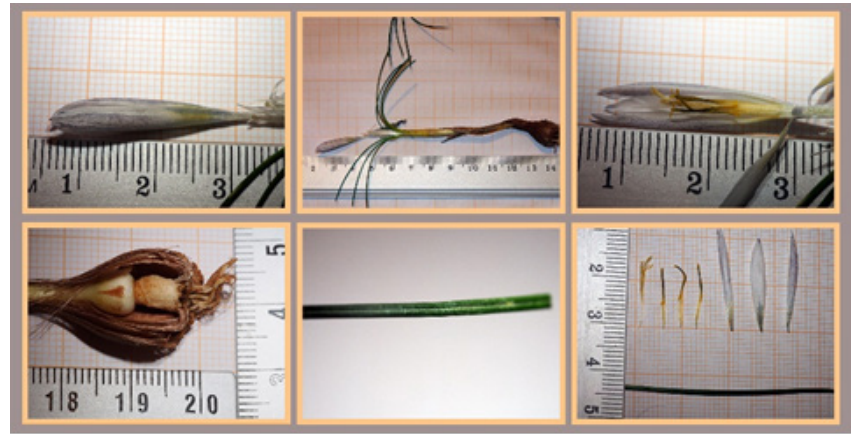

Figure 36 C. b var. youninensis flower parts variations.

\section{Results}

In this study, Crocus baalbekensis var. decorus, fluctus, flavoalbum, makniensis, youninensis, rasbaalbekensis, rihaensis, shaathensis, shlifensis, tnaiyetensis, subsp. ahlansis, anthopotamus, fakihansis, harbatansis, and rassomensis, are discovered, scrutinized, and added to the Lebanese flora for the first time.

\section{Flowering season}

Middle of December till the first week of February.

\section{Location of the Varieties and Subspecies (Figure 4)}

Crocus baalbekensis subsp. ahlansis K. Addam \& M. Bou-Hamda subsp. nov
Ain Ahla (Shaath)
1) Lat 34.133617 Lon 36.294929 Alt $1001 \mathrm{~m}$
2) Lat 34.134972 Lon 36.296307 Alt $1005 \mathrm{~m}$

Crocus baalbekensis subsp. anthopotamus K. Addam \& M. BouHamdan subsp. nov

Ras Baalbek

1) Lat 34.256843 Lon 36.429251 Alt $1043 \mathrm{~m}$

2) Lat 34.257653 Lon 36.433624 Alt $1146 \mathrm{~m}$. 
Crocus baalbekensis subsp. fakihansis K. Addam \& M. BouHamdan subsp. nov

Fakiha: Lat 34.25064 Lon 36.41377 Alt $1291 \mathrm{~m}$, Lat 34.25281 Lon 36.40974 Alt $1003 \mathrm{~m}$.

Ras Baalbek: Lat 34.253688 Lon 36.43467 Alt 1079 m.

Crocus baalbekensis subsp. harbatansis K. Addam \& M. BouHamdan subsp. nov

Harbata, Lat 34.169874 Lon 36.301313 Alt 971 m. Lat 34.152837 Lon 36.294159 Alt $991 \mathrm{~m}$.

Makneh, Lat 34.05966 Lon 36.19632 Alt 1077 m.

Crocus baalbekensis subsp. rassomensis K. Addam \& M. BouHamdan subsp. nov

Ras Baalbek

1) Lat 34.256843 Lon 36.429251 Alt $1043 \mathrm{~m}$.

2) Lat 34.25765 Lon 36.433624 Alt $1146 \mathrm{~m}$.

Crocus baalbekensis var. decorus K. Addam \& M. Bou-Hamdan var.nov

Makneh

1) Lat 34.058965 Lon 36.201782 Alt $1093 \mathrm{~m}$.

2) Lat 34.055415 Lon 36.21324 Alt $1132 \mathrm{~m}$.

Crocus baalbekensis var. flavo-album K. Addam \& M. BouHamdan var.nov

Makneh, Lat 34.058627 Lon 36.201245 Alt 1092 m, Ras Baalbek, Lat 34.257241 Lon 36.433485 Alt $1136 \mathrm{~m}$.

Crocus baalbekensis var. fluctus K. Addam \& M. Bou-Hamdan var.nov

Makneh

1) Lat 34.05942 Lon 36.20325 Alt $1097 \mathrm{~m}$.

2) Lat 34.056102 Lon 36.212437 Alt $1129 \mathrm{~m}$.

Crocus baalbekensis var. makniensis K. Addam \& M. BouHamdan var.nov

Makneh

1) Lat 34.058979 Long 36.201917 Alt $1094 \mathrm{~m}$.

2) Lat 34.055977 Long 36.213732 Alt $1134 \mathrm{~m}$.

Crocus baalbekensis var. rasbaalbekensis K. Addam \& M. BouHamdan var.nov

Ras Baalbek

1) Lat 34.25654 Lon 36.434494 Alt $1132 \mathrm{~m}$.

2) Lat 34.265137 Lon 36.433982 Alt $1023 \mathrm{~m}$.

3) Lat 34.251297 Lon 36.413147 Alt $1046 \mathrm{~m}$.

Crocus baalbekensis var. rihaensis K. Addam \& M. Bou-Hamdan var.nov

Riha

1) Lat 34.139694 Lon 36.219908 Alt $1020 \mathrm{~m}$.

2) Lat 34.147104 Long 36.215451.
Alt 1028 m. Makneh, Lat 34.058807 Long 36.201449 Alt 1093m.

Crocus baalbekensis var. shaathensis K. Addam \& M. BouHamdan var.nov

Shaath

1) Lat 34.138766 , Long 36.228458 , Alt $1034 \mathrm{~m}$.

2) Lat 34.138114 Long 36.223897 Alt $1016 \mathrm{~m}$

3) Lat 34.14589 Long 36.232181 Alt $970 \mathrm{~m}$.

Crocus baalbekensis var. shlifensis K. Addam \& M. Bou-Hamdan var. nov

Shlifa

1) Lat 34.094397 Lon 34.093151 Alt $1078 \mathrm{~m}$.

2) Lat 36.081379 Lon 36.083557 Alt $1104 \mathrm{~m}$.

Crocus baalbekensis var. tnaiyetensis K. Addam \& M. BouHamdan var.nov

Tnaiyet el ras, Lat 34.255403 Lon 36.435337 Alt 1092 m, Ras Baalbek, Lat 34.254719 Lon 36.432813 Alt $1081 \mathrm{~m}$.

Crocus baalbekensis var. youninensis K. Addam \& M. BouHamdan var.nov

Younine

1) Lat 34.116676 Long 36.250207 Alt $1017 \mathrm{~m}$.

2) Lat 34.117789 Long 36.242395 Alt $999 \mathrm{~m}$.

Makneh, Lat 34.058915 Long 36.201655 Alt 1093 m.

\section{Habitat}

The new Varieties and Species share their growth place and habitat with C. baalbekensis.

Cold semi-dry climates are epitomized by rainless summers and wetter cold winters (temp -1 to $36^{\circ} \mathrm{C}$ ) with some snowfall (annual rainfall rate $150-450 \mathrm{ml}$ ), high elevations: $700-1200 \mathrm{~m}$ (up to $1500 \mathrm{~m}$ ). When the blooming of Crocus cancellatus var. damascenus fades, the varieties and subspecies of Crocus baalbekensis start to bloom. It was noticeable that they were not propagating and present to the south of latitude 34.040000. They grow in dry rocky slopes, scrub clearings, tundra (absence of trees) in mountains with very dry soil in summer and semi-wet during blooming. All of them are distributed sporadically along the slopes, together with Ixiolirion tataricum, Eryngium desertorum, Scandix stellate, Eminium spiculatum, Aristolochia maurorum, Atractylis cancellate, Carthamus nitidus, Filago contract, Filago desertorum, Koelpinia linearis, Phagnalon linifolium, Biebersteinia multifida, Salvia palaestina, Stachys nivea, Stachys palaestina, Postia lanuginose, Scilla hanburyi, Alcea damascene, Scilla hanburyi, Alcea damascene, Scorzonera phaeopappa, Malva neglecta, Orchis collina, Roemeria hybrida, Alkanna strigose, Gastrocotyle hispida, Chorispora purpurascens, Astrodaucus orientalis, Bupleurum postii, Echinophora tenuifolia, Erucaria boveana, Malcolmia crenulate, Malcolmia exacoides, Matthiola longipetala, Ankyropetalum coelesyriacum, Gypsophila ruscifolia, Convolvulus galacticus, Achillea fragrantissima, Anthemis scariosa, Artemisia herba-alba, Telmissa microcarpa, Euphorbia aleppica, Euphorbia petiolate, Astragalus roussaeanus, Astragalus tribuloides, Medicago radiates, Erodium gaillardotii, Lythospermum tenuiflorum, Onosma aleppica, Rochelia disperma,Crocus cancellatus damascenus, Ballota damascene, Thymus syriacus, Matthiola damascene, Capparis 
spinosa parviflora, Cleome ornithopodiodes, Colchicum deserti syriaci, Adonis dentata, Consolida orientalis, Consolida pusilla and Lygia pubescens, Centaurea dumulosa, Centaurea virgata squarrosa, Cousinia postiana, Cousinia ramosissima.

\section{Etymology}

Most of the varieties and subspecies epithets are ascribed to the names of villages they were found in such as Ras Baalbek, Harbata, Makneh, Fakiha, Ain Ahla (Shaath), Younine, Riha, Shaath, Shlifa, and Tnaiyet el ras. Others like C. b. subsp. anthopotamus was named due to coverage of the yellow color on its segments thus named Yellow crocus. Moreover, C. b. subsp. Rassomensis epithet is attributed to the old Greek name of Ras Baalbek, Rasoum. Also, C. b. var. decorus was named according to the colors and embellishments present on the petals. C. b. var. flavo-album was named according to the white and yellow color of the segments. C. b. var. fluctus was named according to the undulations in the shape of its corm tunic.

\section{Voucher Specimen}

Fifteen dried sample voucher specimens (Holotypes) were deposited in K. Addam's Herbarium Arts, Sciences and Technology University in Lebanon.

Holotype 1: Crocus baalbekensis subsp. ahlansis K. Addam \& M. Bou-Hamdan. Accession No.: 25-12-18-58-004, collected by Mr. Mounir Bou-Hamdan at 22/I/2017 (Figure 37a).

Holotype 2: Crocus baalbekensis subsp. anthopotamus K. Addam \& M. Bou-Hamdan. Accession No.: 4-1-19-58-002, collected by Mr Mounir Bou-Hamdan at 4/I/2019 (Figure 37b).

Holotype 3: Crocus baalbekensis subsp. fakihansis K. Addam \& M. Bou-Hamdan. Accession No.: 5-2-17-58-002, collected by Mr. Mounir Bou-Hamdan at 5/II/2017 (Figure 37c).

Holotype 4: Crocus baalbekensis subsp. harbatansis K. Addam \& M. Bou-Hamdan. Accession No.: 17-12-17-58-003, collected by Mr Mounir Bou-Hamdan at 17/XII/2017 (Figure 37d).

Holotype 5: Crocus baalbekensis subsp. rassomensis K. Addam \& M. Bou-Hamdan. Accession No.: 4-1-18-58-002, collected by Mr. Mounir Bou-Hamdan at 4/I/2018 (Figure 37e).

Holotype 6: Crocus baalbekensis var. decorus K. Addam \& M. BouHamdan. Accession No.: 25-12-18-58-001, collected by Mr. Mounir Bou-Hamdan at 25/XII-2018 (Figure 37f).

Holotype 7: Crocus baalbekensis var. flavo-album K. Addam \& M. Bou-Hamdan. Accession No.: 4-1-18-58-001, collected XII by Mr. Mounir Bou-Hamdan at 22/I/2017 (Figure 37g).

Holotype 8: Crocus baalbekensis var. fluctus K. Addam \& M. BouHamdan. Accession No.: 25-12-18-58-002, collected by Mr. Mounir Bou-Hamdan at 25/XII-2018 (Figure 37h).

Holotype 9: Crocus baalbekensis var. makniensis K. Addam \& M. Bou-Hamdan. Accession No.: 5-2-17-58-001, collected by Mr. Mounir Bou-Hamdan at 5/II/2017 (Figure 37i).

Holotype 10: Crocus baalbekensis var. rasbaalbekensis K. Addam \& M. Bou-Hamdan. Accession No.: 4-1-19-58-001, collected by Mr. Mounir Bou-Hamdan at 4/I/2019 (Figure 37j).

Holotype 11: Crocus baalbekensis var. rihaensis K. Addam \& M. Bou-Hamdan. Accession No.: 17-12-17-58-001, collected by Mr. Mounir Bou-Hamdan at 17/XII/2017 (Figure 37k).
Holotype 12: Crocus baalbekensis var. shaathensis K. Addam \& M. Bou-Hamdan. Accession No.: 17-12-17-58-002, collected by Mr. Mounir Bou-Hamdan at 17//2017 (Figure 371).

Holotype 13: Crocus baalbekensis var. shlifensis K. Addam \& M. Bou-Hamdan. Accession No.: 3-2-19-58-001, collected by Mr. Mounir Bou-Hamdan at 3/II/2019 (Figure 37m).

Holotype 14: Crocus baalbekensis var. tnaiyetensis K. Addam \& M. Bou-Hamdan. Accession No.: 25-12-18-58-003, collected by Mr. Mounir Bou-Hamdan at 25/XII-2018 (Figure 37n).

Holotype 15: Crocus baalbekensis var. youninensis K. Addam \& M. Bou-Hamdan. Accession No.: 22-1-17-58-001, collected by Mr. Mounir Bou-Hamdan at 22/I/2017 (Figure 37o).

\section{Pictures and Drawings}

The pictures were captured by Mr. Mounir Bou-Hamdan and the Photoshop interventions were made by Miss Joumana Itani.

\section{Discussion}

All new Varieties and Subspecies resemble Crocus baalbekensis but vary in specific anatomical and ecological characters. Each one of these new taxa has some precise (singular) distinctions in taxonomy that makes it rise to the level of a Variety or a Species. Nonetheless, it was difficult for us to adopt a differentiation mechanism to decide this level. Determinedly, we adopted this mechanism for differentiation and nomenclature:

The subspecies of Crocus baalbekensis have been classified as Subspecies on the base of their specific anatomic data that differs from that of C. baalbekensis by the outer layer of the corm tunic (consisting of parallel fibers not glued together, with cross-links between them), measurements, and colors of the components of the flower and leaves.

The varieties of Crocus baalbekensis have been classified as Variety based on their specific anatomic data that differ from that of C. baalbekensis by the outer layer of the corm tunic (consisting of parallel fibers glued together in whole tunic, or of partial areas as tufts of glued fibers and tufts of non-glued fibers with cross-links between them), measurements, and colors of the components of the flower and leaves.

The differences between the new taxa are annotated at length in their description above, but some ecological and important miscellaneous information will be discussed.

All the new taxa share the same distribution area and have the same blossoming time and thrive in cold semi-dry climate. They are epitomized by rainless summers and wetter cold winters. The annual rainfall rate is $150-450 \mathrm{ml}$ except C. b. var. shlifensis $(400-600 \mathrm{ml})$. When the blooming of Crocus cancellatus var. damascenus fades, the varieties and subspecies of Crocus baalbekensis start to bloom. It was noticeable that they were not propagating and present to the south of latitude 34.040000 . C. balbekensis and all its varieties, subspecies, and formas do not grow under trees or shrubs neither in the shade. They spread up to a $1500 \mathrm{~m}$ height where the corms of two kinds were found after the flowering time in the plains of Arsal.

The colors of the flowers change depending on the proportion of rain, some decorations and secondary colors are not visible or lackluster in the case of low humidity of the soil, while clearly visible in the case of dirt saturated with moisture. 
C. baalbekensis \& C. b. var. makniensis effloresce before others in the group at the first half of December, while the rest of the group starts blooming from 20 December till 10 February.
In all C. baalbekensis group the inner spathe is a white membrane consisting of two symmetrical parts surrounding the segment tube. In rare case a flower of $\mathrm{C}$. baalbekensis was found containing 10 sepals, 5 stamens and 2 styles.

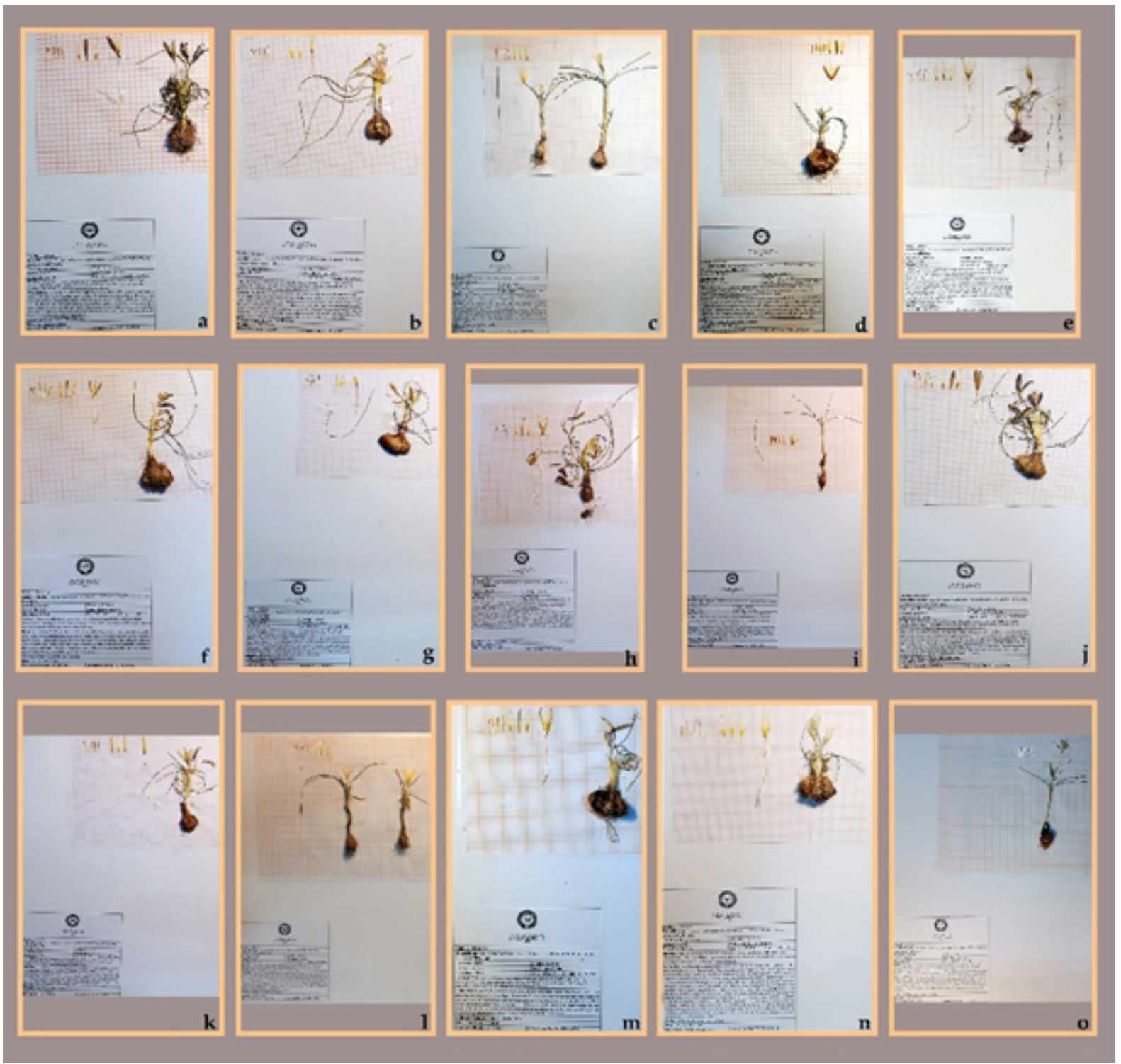

Figure 37 Voucher Specimen of all the Holotypes were deposited in K.Addam's Herbarium Arts, Sciences and Technology University in Lebanon.

\section{Recommendations}

While most crocusologists lament the loss of habitat and species, only few actions are undertaken on the ground to hinder the loss of crocus biodiversity. Therefore, a plethora of actions must be accentuated and reinforced in order to aid reverse the trend politically, technically, and financially. Fortunately, our new records are lavish in thousands and are safely present due to the following conditions:

a. The presence of extremely harsh environmental conditions as it grows in highly mountainous regions and rocky places. b. The place lies on distant mountain terrains that make the access challenging.

c. The inauspicious political conditions specifically reaching the Syrian borders where the war is in action.

d. The absence of ecotourism in addition to sports and touristic activities. $^{8}$

\section{Measurements}

i. Funding to ensure, research, and aptly manage and monitor such areas. 
ii. Sharing of plants, seeds, and pollen among crocus farmers and botanical gardens.

iii. Raising awareness by introducing educational and social events, news jacking, and spreading brochures. These awareness campaigns should be presented for people in general and village men/women in particular to obstruct fires that might happen because of the garbage thrown by people in these mountains.

iv. Stressing on the importance of employing keen research about the new world records of this genus (crocus) in this rural area because of its profusion. ${ }^{8,3}$

\section{Conclusion}

Fifteen new world record Crocus baalbekensis var. decorus, fluctus, fulvum-album, makniensis, youninensis, rasbaalbekensis, rihaensis, shaathensis, shlifensis, tnaiyetensis, subsp. ahlansis, anthopotamus, fakihansis, harbatansis, and rassomensis, joined the Lebanese flora and particularly the Iridaceae family. The validation for the existence of these new Varieties and Subspecies were verified by illustrated morphologic description, more than 20 years of field work, three years of observation, phenology, a host of locations, the existence of countless quantities of the new species. The voucher specimens (representative dried sample) of the plant were deposited in K. Addam's Herbarium at Arts, Sciences and Technology University in Lebanon, collected, and identified by Mr. Mounir Bou-Hamdan, and prepared for preservation in the Herbarium by Dr. Khodr Addam.

\section{Acknowledgments}

The team would like to thank Ms. Nisreen Sabbagh, an AUL research member, for her hard efforts in editing and proofreading this publication. It would also like to thank Miss. Joumana Itani for her assistance in drawing the illustrations as well as all those who helped in the success of this publication.

\section{Research involving human participants and/ or animals}

This publication does not contain any studies on human participants or animals performed by any of the authors.

\section{Informed Consent}

Informed consent was obtained from all participants included in the study.

\section{Remarks}

NB. If the pictures of the publication were not clear enough, we would like to inform you that we will upload high resolution pictures in the briefcase of the paper when published in Researchgate. Therefore, you can be able of encountering additional details that will meet the taxonomical requirements of scholars and scientists working in this field.

\section{Funding}

None.

\section{Conflicts of interest}

The authors declare that they have no conflict of interest.

\section{References}

1. Addam K, Sabbagh N, Bou-Hamdan M, et al. Phytogeography, population, habitat, ecology, threat and conservation action of Orchis anatolica Boiss. in Lebanon. International Journal of Applied Research. 2018;4:34-46.

2. Addam K, Bou-Hamdan M, Ibrahim S, et al. Ophrys Omegaifera Subsp. Gharifensis (Orchidaceae), a new subspecies from Lebanon. Journal of Botanical Research. 2013;4(1):25-27.

3. Addam K, Bou-Hamdan M, Alameh MY, et al. Orchis Troodi (Renz) P. Delforge, Orchis Sitiaca (Renz) P. Delforge and Orchis Anatolica Subsp. Albiflora Subsp. nov K. Addam \& M. Bou-Hamdan, three new rare Orchids Joined the Lebanese Flora. International Journal of Botany Studies. 2017;2(6):221-228.

4. Addam K, Mohamad H, Bou Hamdan M, et al. Cyclamen persicum f. puniceum (Gleason) Grey-Wilson: new plant record joined the Lebanese Flora. International Journal of Botany Studies. 2017;2(4):12-15.

5. Addam K, Girgis E, Bou-Hamdan M, et al. Five records added to the Lebanese native Orchids: Ophrys Omegaifera Subsp. Algarvensis, Basilissa, Fleischmanii, Vasonica and Ophrys Polycratis (Orchidaceae). Journal of Ecology and Environmental Sciences. 2016;7(3):180-185.

6. Addam K, Al-Zein MS, Bou-Hamdan M, et al. A new record: Cyclamen Persicum Mill. var. Autumnale Grey-Wilson was added to the native Lebanese Flora. American Scientific Research Journal for Engineering, Technology, and Sciences (ASRJETS). 2016;26(4):186-194.

7. Addam K, Sabbagh N. Ophrys holoserica (Burm. f.) Greuter subsp. Shoufensis subsp. nov K.Addam \& M. Bou-Hamdan(ORCHIDACEAE), A new world record from Lebanon. International Journal of Botany Studies. 2018;3(6):25-32.

8. Addam K. Crocus baalbekensis K. Addam \& M. Bou Hamdan sp. nov and its three forms (IRIDACEAE), new endemic species and forms from Lebanon, joined the Lebanese Flora. MOJ Eco Environ Sci. 2019;4(2):75-83.

9. Christenhusz MJ, Byng JW. The number of known plants species in the world and its annual increase. Phytotaxa. 2016;261(3):201-217.

10. Coșkun F, Selvi S, Satil F. Phylogenetic relationships of some Turkish Crocus (Iridaceae) taxa based on morphological and anatomical characters. Turkish Journal of Botany. 2010;34(3):171-178.

11. Erol O, Kaya Hb, Şik L, et al. The genus Crocus, series Crocus (Iridaceae) in Turkey and 2 East Aegean islands: a genetic approach. Turkish Journal of Biology. 2014;38(1):48-62.

12. Coşkun F, Selvi S, Satil F. Phylogenetic relationships of some Turkish Crocus (Iridaceae) taxa based on morphological and anatomical characters. Turkish Journal of Botany. 2010;34(3):171-178.

13. Tawney CH, Penzer NM. The ocean of story. Priv. Print for subscribers only by CJ Sawyer, Limited; 1924. 13 p.

14. Kandemir N. Comparative leaf anatomy of some endemic Crocus L. taxa from Turkey. Bangladesh Journal of Botany. 2011;40(2):155-162.

15. Wani ZA, Kumar A, Sultan P, et al. Mortierella alpina CS10E4, an oleaginous fungal endophyte of Crocus sativus L. enhances apocarotenoid biosynthesis and stress tolerance in the host plant. Scientific reports. 2017;7(1):8598.

16. Wani ZA, Ahmad T, Nalli Y, et al. Porostereum sp., Associated with Saffron (Crocus sativus L.), is a latent pathogen capable of producing phytotoxic chlorinated aromatic compounds. Current microbiology. 2018;75(7):880.

17. Candan F, Sik L, Kesercioglu T. Cytotaxonomical studies on some Crocus L. taxa in Turkey. African Journal of Biotechnology. 2009;8(18). 
18. Peter KV. Genesis and evolution of horticultural crops. Saffron Evolution, Kruger Brentt Publisher Uk. Ltd; 2017

19. Alavi-Kia SS, Mohammadi SA, Aharizad S, et al. Analysis of genetic diversity and phylogenetic relationships in Crocus genus of Iran using inter-retrotransposon amplified polymorphism. Biotechnology \& Biotechnological Equipment. 2008;22(3):795-800.

20. Kandemir N. Morphology, anatomy and ecology of critically endangered endemic Crocus pestalozzae Boiss.(Iridaceae) in North-West Turkey. Bangladesh Journal of Botany. 2009;38(2):127-32.

21. Petersen G, Seberg O, Thorsøe S, et al. A phylogeny of the genus Crocus (Iridaceae) based on sequence data from five plastid regions. Taxon. 2008;57(2):487-499.

22. Karaismailoğlu Mc, Şik L, Çiftçi A, et al. Seed structure of some taxa of the genus Crocus L. (Iridaceae) series Crocus. Turkish Journal of Botany. 2018;42(6)

23. Raca IL, Ljubisavljević I, Jušković M, et al. Comparative anatomical study of the taxa from series Verni Mathew (Crocus L.) in Serbia. Biologica Nyssana. 2017;8(1).
24. The Country of crocuses.

25. Erol O, Kaya $\mathrm{Hb}$, Şik L, et al. The genus Crocus, series Crocus (Iridaceae) in Turkey and 2 East Aegean islands: a genetic approach. Turkish Journal of Biology. 2014;38(1):48-62.

26. Erol O, Can L, Ş1 L. Crocus demirizianus sp. nov. from northwestern Turkey. Nordic Journal of Botany. 2012;30(6):665-667.

27. Osman Erol, Doerte Harpke, Hasan Yildirim. A new Crocus L. (Iridaceae) species from SE Turkey, based on morphological and molecular data. Phytotaxa. 2015;239(3): 223-232.

28. Post GE. Flora of Syria, Palestine and Sinai. 1933;2:574.

29. Tohmé G, Tohmé H. Illustrated flora of Lebanon. 2nd ed. Beirut: CNRS Lebanon publications; $2014610 \mathrm{p}$.

30. Mouterde P. New flora of Lebanon and Syria. Beyrouth, Dar El-Machreq SARL; 1983:365-578.

31. Mathew B. The Crocus: a revision of the genus Crocus (Iridaceae). Timber Pr; 1983:220-222. ISBN: 091730423. 